\title{
SIMAKRAMA sebagai Portal Informasi Banjar Pakraman Berbasis Web
}

\author{
Kadek Dwi Pradnyani Novianti ${ }^{1}$, Ricky Aurelius Nurtanto Diaz ${ }^{2}$ \\ Program Studi Sistem Informasi \\ STMIK STIKOM Bali \\ Depasar, Indonesia \\ novianti@stikom-bali.ac.id, ㄹicky@,stikom-bali.ac.id
}

\begin{abstract}
Banjar Pakraman merupakan budaya sosial masyarakat Bali sebagai warisan budaya yang secara turun temurun tetap dijaga. Sebagai pelaksana Banjar Pakraman terdapat krama banjar dan pengurus banjar. Namun, semakin hari komunikasi pengurus banjar dengan krama banjar untuk menyampaikan informasi baik mengenai pelaksanaan kegiatan atau undangan kegiatan semakin susah dilakukan. Hal ini disebabkan oleh tingginya tingkat aktivitas pengurus dan krama banjar sehingga penyampaian informasi memakan cukup banyak waktu. Dalam upaya mengatasi permasalahan ini, maka dengan pemanfaatan teknologi dapat dibangun aplikasi SIMAKRAMA berbasis web yang dapat diakses dimanapun dan kapanpun. Dengan adanya aplikasi SIMAKRAMA, pengurus dapat menghemat waktu untuk menyampaikan informasi kepada krama banjar. Aplikasi SIMAKRAMA dibangun menggunakan framework CodeIgnitier dan penyimpanan menggunakan MySQL. Fitur yang dapat diakses antara lain informasi kegiatan dalam Menu Berita dan Menu Pengaduan untuk penyampaian keluha krama banjar terkait lingkungan Banjar Pakraman. Hasil pengujian menggunakan Blackbox Testing menunjukan bahwa fungsional proses dalam SIMAKRAMA dapat berjalan dengan baik.
\end{abstract}

Kata kunci-SIMAKRAMA, Banjar Pakraman, Communication, Website

\section{Pendahuluan}

Bali memiliki beragam kearifan lokal yang masih terus berjalan dalam kehidupan masyarakat. Adat istiadat yang merupakan warisan dari leluhur selalu diresapi dan diimplementasikan sampai dengan saat ini. Salah satunya adalah banjar pakraman yang merupakan sebuah budaya kehidupan bermasyarakat bagi penduduk di Bali. Banjar pakraman secara mendasar adalah pembagian wilayah di Bali secara administratif. Dalam banjar pakraman dikenal dengan istilah manyama braya. Menyama braya merupakan sebuah nilai atau norma yang menganggap bahwa anggota krama banjar pakraman merupakan saudara sehingga menjadi sebuah kewajiban untuk saling tolong menolong dan bergotong royong [1].

Terdapat banyak kegiatan yang dapat dilakukan di lingkungan banjar pakraman, misalnya pembangunan tempat suci, suka duka untuk kematian (ngaben), kelahiran ataupun pernikahan (pawiwahan) [2]. Agar dapat melakukan interaksi antar krama banjar biasanya terdapat pengurus banjar yang bertugas untuk menyampaikan informasi kepada krama banjar yang ada dalam lingkungannya. Namun saat ini penyampaian informasi kepada krama banjar menjadi tidak efektif dikarenakan oleh tingginya tingkat aktivitas pekerjaan yang dimiliki oleh masing-masing krama banjar. Hal ini menyebabkan budaya menyama braya menjadi sangat jarang untuk dilakukan lagi. Tingginya tingkat aktivitas berbanding terbalik dengan tingkat komunikasi untuk penyampaian informasi. Dampaknya adalah kebutuhan informasi yang semakin bertambah tidak mampu diakomodasi oleh pengurus banjar secara manual. Dengan cara manual dalam berkomunikasi, banyak waktu yang diperlukan untuk mendatangi setiap rumah krama banjar yang ada dalam lingkungan banjar pakraman tersebut.

Melihat kondisi yang terjadi, maka kegiatan menyame braya dalam banjar pakraman kemungkinan akan mulai ditinggalkan. Pemanfaatan teknologi sebagai upaya dalam penyelesaian masalah ini dapat menjadi alternatif solusi yang dapat dilakukan. Perkembangan teknologi yang semakin pesat dapat membantu pekerjaan manusia di berbagai bidang. Krama banjar dalam kehidupan menyama braya dapat menggunakan website sebagai media penyampaian informasi. Website adalah salah satu aplikasi yang berisikan dokumen-dokumen multimedia (teks, gambar, suara, animasi, video) didalamnya yang menggunakan protocol HTTP (hypertext transfer protocol) dan untuk mengaksesnya mengunakan perangkat lunak yang disebut browser [3]. Website tidak hanya dapat diakses melalui sebuah PC namun juga dapat dilakukan melalui sebuah smartphone yang memiliki browser untuk mengakses sebuah halaman website. Hal ini dapat dilakukan mengingat smartphone tidak lagi menjadi barang mewah dan dapat dengan mudah dijangkau oleh masyarakat. Penyampaian informasi kepada krama banjar dalam desa pakraman dapat dilakukan melalui sebuah website yang dapat mengakomodasi kebutuhan informasi yang diperlukan.

Pengembangan website SIMAKRAMA digunakan untuk mengakomodasi permasalahan yang telah 
dipaparkan sebelumnya. Pengembangan website ini bertujuan untuk mengkonversi proses yang telah berjalan sebelumnya menjadi proses yang lebih praktis dengan memanfaatkan teknologi tepat guna. Melalui penelitian ini diperoleh hasil sebuah website SIMAKRAMA sebagai portal informasi Banjar Pakraman.

\section{TINJAUAN PUSTAKA}

Beberapa penelitian yang telah dilakukan berkaitan dengan pengembangan aplikasi layanan informasi bagi masyarakat sebagai berikut.

Sistem Informasi Layanan Desa (SiLISA) dikembangkan sebagai sebuah aplikasi layanan informasi berbasis SMS Gateway Multi-Direct. Melalui sistem ini, perangkat desa, organisasi desa, komunitas desa dan masyarakat dapat saling berkomunikasi untuk menyampaikan suatu informasi yang perlu untuk disampaikan. SiLISA menggunakan format SMS tertentu untuk kepentingan penyampaian saran sehingga dapat dikelompokan dan disampaikan sesuai dengan kewenangan suatu pihak. Selain itu SiLISA dapat digunakan untuk poling pengambilan keputusan yang harus melibatkan semua warga. Kelebihan dari SiLISA bahwa aplikasi SMS Gateway ini dikembangkan secara dinamis dan terintegrasi sehingga dapat digunakan sesuai dengan kebutuhan informasi dari masingmasing penggunanya [4].

SIKADES (Sistem Informasi Kependudukan Desa) merupakan salah satu penelitian yang dilakukan sebagai solusi penanganan keluhan dan pengaduan masyarakat. SIKADES yang dibuat menggunakan teknologi web mobile, dimana pengguna dapat mengakses SIKADES melalui perangkatperangkat yang dapat terhubung dengan internet seperti handphone dan komputer. Kelebihan dari sistem ini adalah pengguna yang dalam hal ini adalah warga dapat melakukan pengajuan surat- surat yang ingin dibuat melalui sistem serta SIKADES juga melibatkan perangkat desa untuk menyetujui pengajuan dari warga. Dengan sistem yang terkomputerisasi, proses pengajuan yang dilakukan dapat berjalan lebih cepat dan efisien sehingga permintaan dari warga dapat segera diselesaikan [5].

Dari penelitian-penelitian yang telah dilakukan, maka penelitian yang saat ini akan dibuat berfokus pada layanan informasi kepada masyarakat di Banjar Pakraman dengan sebuah portal layanan dan memanfaatkan teknologi website aplikasi yang sudah sangat berkembang dan mudah dijangkau oleh krama banjar. Banjar Pakraman sebagai pusat kehidupan bermasyarakat diharapkan dapat menjadi fasilitas informasi bagi masyarakat. Dan juga dengan penerapan teknologi diharapkan dapat turut mengembangkan budaya yang ada, dalam hal ini Banjar Pakraman, serta menjaga kerukunan antar masyarakat.

\section{LANDASAN TEORI}

\section{A. Banjar Pakraman}

Banjar adalah ikatan sekelompok masyarakat yang tingkatannya berada di bawah Desa Adat. Seperti halnya Desa Adat, Banjar juga memiliki peraturan yang mengikat anggotanya. Umumnya anggota Banjar ditentukan berdasarkan domisili yang berdekatan, walaupun tidak tertutup kemungkinan warga perantauan yang bertempat tinggal nan jauh tetap menjadi anggota dan terikat dengan peraturan Banjar di desa asalnya.

Sebagai pusat dari Banjar, di Bali dikenal adanya Bale Banjar. Kesatuan sosial itu diperkuat oleh kesatuan adat dan upacara-upacara keagaman. Di daerah pegunungan, sifat keanggotaan Banjar hanya terbatas pada orang yang lahir di wilayah Banjar tersebut. Sedangkan di daerah datar, sifat keanggotaannya tidak tertutup dan terbatas kepada orang-orang asli yang lahir di Banjar itu. Orang dari wilayah lain, atau lahir dari wilayahlain, dan kebetulan menetap di Banjar bersangkutan, dipersilakan untuk menjadi anggota (Krama Banjar), jika yang bersangkutan ingin dan mau bergabung di Banjar bersangkutan. Kemudian, Kelihan Banjar (pemimpin) mengkehendaki orang tersebut bergabung dalam Banjar bersangkutan, maka orang yang bersangkutan berhak bergabung dalam Banjar bersangkutan. Pusat dari Banjar, Bale Banjar, dimana warga Banjar bertemu pada hari-hari yang tetap atau bisa juga pada saat adanya upacara keagamaan, Banjar di kepalai oleh seorang kepala yang disebut Kelihan Banjar. Ia dipilih dengan masa jabatan tertentu oleh warga Banjar. Tugas Kalihan Banjar tidak hanya menyangkut segala urusan dalam lapangan kehidupan sosial dari Banjar sebagai suatu komuniti, tapi juga lapangan kehidupan keagamaan. Tidak hanya itu ia juga harus memecahkan masalah yang menyangkut adat. Kadang Kelihan Banjar juga mengurus hal-hal yang sifatnya berkaitan dengan administrasi pemerintahan desa. Contonya: mengurus surat izin keramaian bila anggotanya akan mengadakan pesta atau upacara keagamaan dan menyelesaikan masalah-masalah sosial seperti perkelahian, perselingkuhan, dan pencurian melalui persidangan secara adat [1].

\section{B. $M y S Q L$}

Relational Database Mangement System (RDBMS) yang didistribusikan secara gratis dibawah lisensi GPL (General Public License). MySQL merupakan turunan salah satu turunan SQL (Structured Query Language) dimana sebuah konsep pengoperasian database, terutama untuk pemilihan/seleksi dan pemasukan data, yang memungkinkan pengoprasian data dikerjakan dengan mudah secara otomatis. MySQL merupakan multiuser database yang menggunakan bahasa Structured Query Language (SQL). SQL (dibaca "essque-el") adalah bahasa standart ANSI (American National Standards Institute), yang digunakan untuk mengakses server database atau lebih dikenal dengan Relational Database Management Systems (RDBMS). Pernyataan-pernyataan SQL digunakan untuk melakukan beberapa tugas seperti : update data pada database, atau menampilkan data dari database. Beberapa software RDBMS dan dapat menggunakan SQL, seperti : Oracle, Sybase, Microsoft SQL Server, Microsoft Access, Ingres, dsb.

\section{Website}

Website adalah salah satu aplikasi yang berisikan dokumen-dokumen multimedia (teks, gambar, suara, animasi, video) didalamnya yang menggunakan protocol HTTP (hyper 
text transfer protocol) dan untuk mengaksesnya mengunakan perangkat lunak yang disebut browser. Beberapa jenis browser yang populer saat ini di antaranya : Internet Expolre yang diproduksi oleh Microsoft, Mozila Firefox, Opera dan Safari yang diperoduksi oleh Apple Browser (perambah) adalah aplikasi yang mampu menjalankan dokumen dokumen web dengan cara diterjemahkan. Prosesnya dilakukan oleh komponen yang terdapat didalam aplikasi browser yang biasa disebut web engine. Semua dokumen web ditampilkan dengan cara diterjemahkan [3].

\section{Framework CodeIgnitier}

Framework adalah abstraksi di dalam sebuah perangkat lunak yang menyediakan fungsi yang generic sehingga dapat dirubah oleh kode yang dibuat user sehingga dapat menyediakan perangkat lunak untuk aplikasi tertentu. Metode MVC adalah sebuah arsitektur yang dapat diimplementasikan secara bebas dengan atau tanpa bahasa pemrograman berorientasi objek. Dengan demikian metode MVC dapat diimplementasikan dalam sebuah framework. CodeIgniter merupakan sebuah framework pemrograman web dengan menggunakan bahasa PHP. Framework ini ditulis dengan menggunakan bahas PHP versi 4 dan versi 5 oleh Rick Ellislab yang menjadi CEO Ellislab, Inc. dan dipublikasikan dengan lisensi di bawah Apache/BSD Open Source. Jadi CodeIgniter adalah framework PHP dan Open Source.

Manfaat yang dapat diambil dengan menggunakan framework CodeIgniter adalah sebagai berikut.

1. Gratis, sesuai dengan semangat Open Source untuk dapat digunakan dan dikembangkan secara bersamasama. Dapat di-download pada alamat http://CodeIgniter.com/downloads/secara gratis, bebas digunakan sesuai persyaratan persetujuan lisensi (lisence agreement) yang bisa dilihat pada website tersebut di atas.

2. Ditulis dengan menggunakan bahasa PHP 4 (untuk versi 1.x.x) dan versi 5 (untuk versi 2.x.x) sehingga mendukung pemrograman dengan bahasa php.

3. Menggunakan metode MVC sebagai prinsip kerjanya sehingga dapat digunakan untuk mengembangkan aplikasi secara efisien dan dinamis serta lebih memudahkan dalam melakukan pemeliharaan aplikasi.

4. Menggunakan URL (Uniform Resource Locator) yang sederhana, bersih, dan SEF (Search Engine Friendly).

5. Memiliki paket library yang lengkap, mendukung fungsi-fungsi database, html, web, e-mail, session, pagination dan lain-lain.

6. Dokumentasi yang lengkap dan jelas, disertakan dalam website resminya dan dapat di-download bersama-sama dengan framework- nya.

7. Komunitas, framework ini didukung oleh banyak pengguna dan pengembang, walaupun awalnya dikembangkan oleh Ellislab, Inc.

8. Bersifat portabel dan dapat dijalankan pada berbagai platform yang mendukung bahasa pemrograman php.

MVC, framework CodeIgniter juga terbagi menjadi tiga bagian utama yaitu :
1. Model, bagian ini berisi kode yang digunakan untuk koneksi dan mengakses database.

2. View, berisi kode-kode HTML dan php yang digunakan untuk menampilkan informasi ke layar browser. Biasanya berisi kode-kode yang berhubungan dengan format tampilan, misalnya huruf, form, warna, dan lain-lain.

3. Controller, berisi kode-kode script yang menjalankan fungsi aturan bisnis aplikasi dan menjadi perantara antara Model dan View serta seluruh sumber daya yang dibutuhkan untuk memproses permintaan layanan HTTP untuk ditampilkan dalam halaman web [6].

\section{HASIL DAN PEMBAHASAN}

Website SIMAKRAMA dibangun untuk membantu pengurus dan krama Banjar Pakraman memperoleh informasi. Setiap pengguna memiliki akses masing-masing ke dalam website sehingga pengguna tersebut dapat melakukan fungsinya masing-masing sesuai dengan kebutuhan informasi yang diperlukan. SIMAKRAMA dapat diakses oleh krama banjar seperti pada Gambar 1 dengan melakukan login terlebih dahulu ke dalam sistem. Apabila krama banjar belum terdaftar maka dapat melakukan registrasi terlebih dahulu.

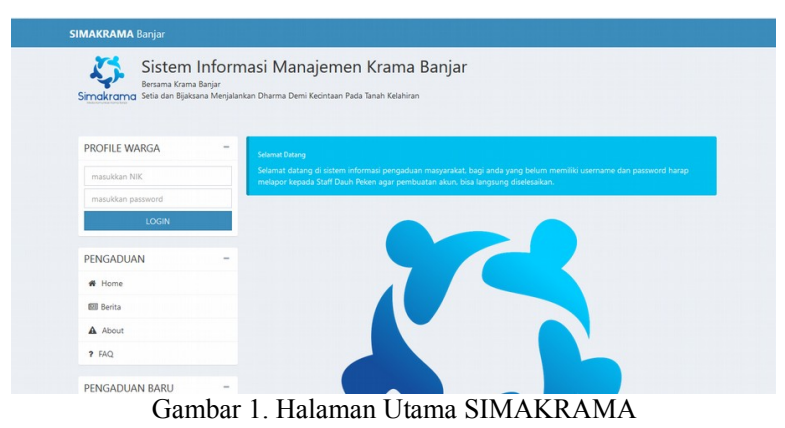

Beberapa fitur yang dapat diakses oleh krama banjar antara lain Berita, Pengaduan, dan Profil Krama Banjar. Pada fitur Berita, krama banjar dapat melihat informasi terkait pelaksanaan kegatan, undangan kegiatan krama banjar, dan informasi rapat banjar. Informasi ini akan diperbaharui oleh pengurus banjar secara realtime, sehingga krama banjar dapat memperoleh informasi yang cepat dan actual. Fitur berita dapat dilihat pada Gambar 2.

Fitur Pengaduan merupakan fitur dimana krama banjar dapat menyampaikan keluhan yang dirasakan seperti pada Gambar 3. Keluhan ini dapat mengenai fasilitas dalam lingkungan banjar seperti jalan rusak, kurangnya tempat sampah, atau balai banjar yang kotor. Selain itu, krama banjar juga dapat memberikan keluhan mengenai keamanan lingkungan banjar pakraman. 

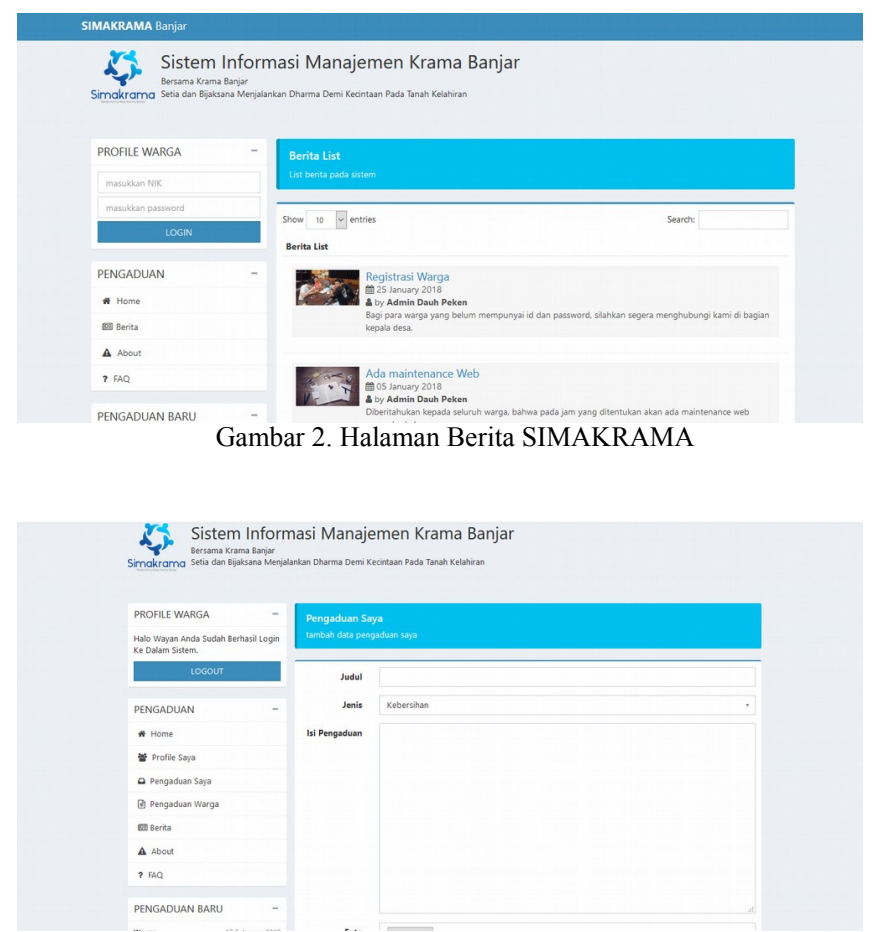

Gambar 3. Halaman Pengaduan SIMAKRAMA

Setiap pengaduan yang diajukan oleh krama banjar akan ditindak lanjuti oleh pengurus banjar. Dimana setiap pengaduan yang diajukan terlebih dahulu akan divalidasi oleh pengurus banjar. Sehingga apabila ada krama banjar yang melakukan pengaduan dengan cara yang tidak benar atau membuat pengaduan palsu, pengurus banjar dapat dengan segera menolak pengaduan tersebut. Bagi pengaduan yang disetujui oleh pengurus banjar akan diberikan konfirmasi tindak lanjut terhadap pengaduan tersebut. Hal ini menyebabkan krama banjar akan segera mengetahui jawaban dari keluhan yang disampaikannya. Tindak lanjut dapat berupa konfirmasi pengurus banjar dapat dili pada Gambar 4.

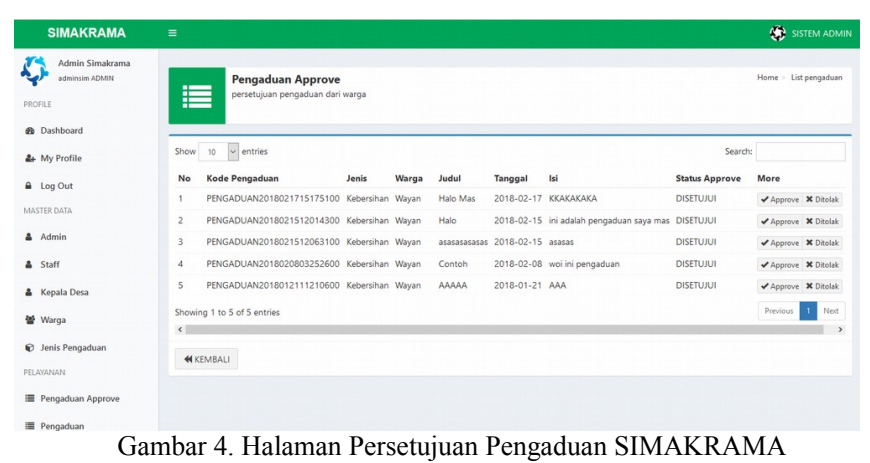

Tahapan terakhir dalam penelitian ini adalah pengujian system. Seperti yang sudah disampaikan sebelumnya, pengujian system dilakukan menggunakan blackbox testing. Hasil pengujian dapat dilihat pada Tabel 1.
TABel 1. Hasil PenguJian

\begin{tabular}{|l|l|l|l|}
\hline No & Proses & \multicolumn{1}{|c|}{ Kasus Uji } & Validasi \\
\hline 1 & Login & $\begin{array}{l}\text { Username dan Password } \\
\text { benar }\end{array}$ & Sesuai \\
\cline { 3 - 5 } & $\begin{array}{l}\text { Username dan Password } \\
\text { salah Sesuai }\end{array}$ & $\begin{array}{l}\text { Halaman berita } \\
\text { menampilkan Sesuai } \\
\text { kegiatan dan undangan } \\
\text { kegiatan }\end{array}$ & \\
\hline 2 & Berita & $\begin{array}{l}\text { Pengaduan dapat disimpan } \\
\text { dan menampilkan pesan } \\
\text { pengaduan telah disimpan }\end{array}$ & Sesuai \\
\hline 4 & Pengaduan \\
\hline
\end{tabular}

\section{SIMPULAN}

Simpulan yang diperoleh adalah website aplikasi SIMAKRAMA dibangun menggunakan framework CodeIgnitier menghasilkan website aplikasi yang memberikan informasi dalam sebuah Banjar Pakraman. Melalui aplikasi SIMAKRAMA dapat digunakan untuk membantu banjar pakraman untuk melakukan komunikasi antar krama banjar secara efektif dan efisien. Melalui Aplikasi SIMAKRAMA ini juga krama banjar dapat melakukan pengaduan yang terkait dengan kondisi di lingkungan Banjar Pakraman.

\section{DAFTAR PUSTAKA}

[1] I. K. Meniarta, W. Masúdi, and A. A. Dwipayana, "Dinamika Sistem Kesejahteraan dan Modal Sosial di Masyarakat Banjar Pakraman- Bali," J. Ilmu Sos. dan Ilmu Polit., vol. 13, no. November, pp. 231-248, 2009.

[2] W. G. Suacana, "Budaya Demokrasi dalam Kehidupan Masyarakat Desa di Bali,” J. Kaji. Bali, vol. 01, no. 01, pp. 88-151, 2011.

[3] M. Suhartanto, "Pembuatan Website Sekolah Menengah Pertama Negeri 3 Delanggu Dengan Menggunakan Php Dan Mysql," $J$. Speed - Sentra Penelit. Eng. dan Edukasi, vol. 4, no. 1, pp. 1-8, 2012.

[4] N. L. Syafiul Muzid, "PENGEMBANGAN SISTEM LAYANAN INFORMASI DESA (SiLISA) TERINTEGRASI BERBASIS SMS GATEWAY Syafiul," Semin. Nas. Teknol. Ind. dan Inform., no. 2010, pp. 407-412, 2015.

[5] I. W. Noviyanto, Fiftin, Tedy Setiyadi, "JURNAL INFORMATIKA Vol. 8, No. 1, Januari 2014,” J. Inform., vol. 8, no. 1, pp. 858-869, 2014.

[6] D. Rahmadiansyah and D. Irwan, "Implementasi Metode Model View Controller Menggunakan Framework Code Igniter dalam Pengembangan Aplikasi Manajemen Depo Petikemas pada Unit Usaha Belawan Logistics Center," Snastikom, no. Snastikom, pp. 1$11,2012$. 